\title{
A Framework for Student Assessment using Applied Simulation
}

\author{
Tony Richardson \\ Massey University - Albany, Auckland, New Zealand
}

\section{t.s.richardson@massey.ac.nz}

\begin{abstract}
There is an ongoing and vigorous debate in academia concerning the role of Universities in the education process and the relationship Universities have with industry. In the broad sense, should we (the Universities) be educating or should we be training?

Not withstanding that debate, it seems undeniable that the study of Information Systems has been spawned from the need to understand both the theoretical and best practice approaches to the creation of computer-based applications. Just as in the undergraduate study of Law, Medicine or Aviation, so too a Bachelor of Information Systems degree without some assessment of acquired practical skills carries little currency in the job marketplace and reflects only a subset of the subject's understanding.
\end{abstract}

Keywords: Simulation, multimedia, rating, employers

\section{Introduction}

This paper puts a case for and suggests an initial framework to develop a simulation software tool to assess both the practical skills and other non-vocational qualities of graduating Information Systems students. The proposed software tool may be useful as an Information and Communications Technology (ICT) industry recruitment aid and as a quality indicator and reality check for University Information Systems courses. This is the beginning of an extensive and ongoing research project.

\section{The Problem}

The structure of Massey University's Information Systems (IS) major is not untypical of similar programmes worldwide. The qualifications consist of a series of related, though not necessarily inter-related courses, each dealing with a particular aspect of IS taken from a management, technology or development viewpoint. Each course is encapsulated within the semester system and each aspect is assessed in isolation from all others by some means, usually a form of individual examination. In several cases the assessment processes have changed significantly of late to accommodate larger numbers of students and fewer academic staff. There has been a notable shift towards objective examinations using machine-marked multiple-choice papers and fewer written

Material published as part of this journal, either on-line or in print, is copyrighted by Informing Science. Permission to make digital or paper copy of part or all of these works for personal or classroom use is granted without fee provided that the copies are not made or distributed for profit or commercial advantage AND that copies 1) bear this notice in full and 2) give the full citation on the first page. It is permissible to abstract these works so long as credit is given. To copy in all other cases or to republish or to post on a server or to redistribute to lists requires specific permission from the publisher at Publisher@InformingScience.org assessments due to the decline in students' English language skills and greater numbers of international students.

In Massey, as in most Universities, a capstone project paper is provided where students can bring together all the knowledge they have gained on 
their individual courses and apply it to a practical application which is often external to the University. This crescendo style project paper is used in many instances as an assessment of the students' abilities to communicate with clients, to analyze a problem domain, to design and develop solutions and to implement those solutions within agreed timeframes. Along the way they work as part of a team, develop that team structure and manage the inevitable and concomitant personnel and productivity issues that arise. All of these aspects are intended to demonstrate the students' holistic IS abilities and to generate the beginnings of a commercial portfolio as a spin off.

What are the problems with this crescendo paper approach?

- Students almost always work on these projects in groups. The assessment and management of group-work is problematic. As highlighted by Elizabeth Burd and Sarah Drummond (Burd \& Drummond, 2001),

- Not all students put in an equal contribution

- When faced with tight deadlines theoretical principals are inevitably abandoned

- There is often strong competition for the role of the chair but students do not know each other well when appointments are made

- Some groups fail to gel. Often these members fail to explain the seriousness of the problem to supervisors for fear of being down-marked.

Often, groups complete their projects locked in adversarial combat and resort to rules and regulations as typified by Otago University (Otago, 2003) to help sort out the mess.

- Assessment is rarely done in real-time. The decision-making process of each student is most often not the focus of assessment but rather the final result of a series of decisions and re-evaluations that culminate in a particular function, design drawing or presentation point.

- Due to their lack of experience, students are unaware of the degree of relative difficulty of their projects and also the potential for their project's environment to be atypical when compared with their post university career in systems development.

- From a potential employer's point of view these "real life" projects may well appear to be largely artificial in nature, providing little of the vagaries and politics that actually make systems development so difficult. As a consequence, courses which are considered by academics as capstone and crescendo become degraded into just another course and employers are forced into using a curriculum vitae showing final grades as a guide to a student's ability and aptitude for IS development.

\section{What do Employers Want?}

Much work has been done to quantify exactly what skills and abilities employers in the ICT (Information and Communications Technology) industry look for when recruiting IT graduates. The results of the various surveys over the years do not seem to radically change, employers responses being typified by Baillie (1999)

\section{"basic programming skills, communication, problem-solving and teamwork"}

Interestingly, Baillie states that, in her study, the method by which most supervisors identified graduates' skill sets were "a combination of curriculum vitae $(\mathrm{CV})$ and intuition", she also states "smaller companies especially tended not to have formal interview techniques nor job specifications against which to measure attributes". She later observes that the soft skills, which were rated 
as very important by $75 \%$ of her respondents, were very rarely incorporated into companies' training programmes.

As Baillie concludes:

From the research undertaken and other studies, it appears that if employers are questioned on their views they will set high standards, but when probed further, these standards are difficult to quantify.

If one extrapolates further, indicators can be defined which are not so much what employers want, but rather the information employers would like to possess before making a job offer to an ICT graduate. These indicators are:

- An indication of aptitude for a specific role.

- An indication of potential for future roles.

- An indication of personality, to detect "square pegs".

- An indication of loyalty

- An indication of motivation

- An indication of ambition and drive

- An indication of personal organizational ability

- An indication of initiative.

- Maybe even an indication of morality and obedience as well as several other factors, all aimed at reducing recruitment costs and selecting and retaining the most appropriate graduate candidates.

Anecdotal evidence taken from the "Big Four" accounting practices in New Zealand confirm the above indicators and also place the annual graduate recruitment costs firmly in the seven figure ballpark.

\section{Reality Check}

ICT employers are demanding well-rounded, competent graduates, equipped with fundamental skills in ICT, an ability to interact with clients, an awareness of general business principles and culture and an aptitude to learn quickly. Several of these skills are not specifically taught on university ICT courses but are learned by students through course management and structure. There is less concrete evidence to support the notion that employers are seeking specific vocational skills in their graduates, though students often quote this as a reason for using particular software or architecture.

All of which endorses the findings that students can often fail to make the connection between skills that they learn at University and business skills they will need in the workplace if these links are not made manifestly clear (Bennett, Dunne, \& Carre, 2000).

In the current environment it is beyond the practical resources of Universities to accurately assess students in the across the board, interrelated and fuzzy terms expressed by employers. It is even further beyond practicalities to assess how students rank on the scale of indicators proposed above, yet this is actually what employers want. Anything else requires a fallback to CV and intuition, which potentially discards many "good fit" students and employs "good on paper" students instead. The typical turnover rate for graduates of $20 \%$ for a medium sized UK ICT em- 
ployer (Fraser-Williams, 2000) indicates this process is failing both employers and graduate employees.

Another factor should be considered here. There is a trend for employers to take on non-ICT graduates in preference to degree holders of Computer Science or Information Systems. A spokesman for Fraser-Williams identifies why this trend may continue and grow:

"The company doesn't just take on IT graduates. This is an ongoing shift and partly reflects making a virtue out of a necessity, since the numbers of students - especially females - selecting IT is not only too low (thanks to the nerdy image of IT) but also, according to national statistics, several points below the average quality of undergraduates in other subjects" (Towner, 2002)

The long-term fix for this situation is complex and systemic, requiring that those concerned:

- Improve the attractiveness of University ICT courses to top academic achievers

- Improve the attractiveness of the ICT industry to women

- Improve the content and delivery of University ICT courses to explicitly teach and assess non vocational as well as vocational skills

- Improve assessment methods to encompass all the indicators mentioned above to feedback into course structure and to add practical credibility to ICT graduates.

This paper addresses only the final point above, the design framework for an interactive simulation model, which could provide an assessment technique, feedback for courses and a suite of indicators for potential graduate employers.

\section{Simulation - A definition}

Simulation has been defined as the imitation of the operation of a real world system over time. By the generation of an artificial history of a system and the observation of that history to draw inferences on the operating characteristics of the real system. (Fakaryildiz, 2002) But it should be clear that, in the context of this paper, any assessment tool must include the operator as part of the simulation. Thus the proposed framework would construct a highly interactive environment, more akin to a flight simulator for pilots than a traffic flow simulator looking for bottlenecks. A system, which encompasses a world of known elements and allows the operator to investigate, interrogate and order those elements to achieve a specified goal. We may also add to our IS simulation those connotations to the word "simulation" as laid out by Chris Elgood (Elgood, 1997):

- A physical means of reproducing, off-the-job, the phenomenon being studied

- A precise focus on a single specified phenomenon

- Absence of direct human opponents, the challenge being 'player versus environment' rather than 'player versus player'.

So, in an IS simulator, exactly as a pilot uses a flight simulator, reacting to instruments and observations, achieving a specified goal through the application of practical skills and theoretical knowledge, would an IS student design an application, structure a database or construct a user interface. That student could be assessed on the result and on how the result was achieved from standpoints based on a predetermined set of criteria and data gathering. 


\section{The Simulated World}

Some work has been done at the synaptic level of the brain (Garlic, 1999), which suggests that there is an improved level of mental modeling using a multimedia construction of teachingmaterials rather than a purely textual approach. The richness of the learning environment, though adding complexity, serves to stimulate the brain's overall experience and facilitate understanding and memory lay-down. The IS simulator would, of necessity be a complex environment enveloping characters, technologies, organizational structures, communication channels, personnel hierarchies and so on. All the essential elements in fact which are required to allow a comprehensive suite of use-case diagrams, or a relational database schema, or a web-based user interface to be generated.

Following an introduction to the scenario, the simulator should allow the student to schedule meetings, interview characters, receive messages, elicit advice etc. The variable level of difficulty determined by a scenario script provided by the assessor on CD or downloaded over a network or the Internet. The possibilities for remote education as well as assessment become obvious here, with various different scripts generating multiple scenarios, perhaps guiding the student with the aid of a virtual mentor.

The simulator could gather data on real-time decision making, logging choices and questioning why those choices were made. The simulator should provide instant feedback on the consequences of operator decisions and also envelope the student operator in an instructive and enjoyable virtual world.

\section{Conclusion}

To some, the idea of assessment by robot is abhorrent. However, we do a disservice to our students by not providing them with an accurate validation of their overall understanding of IS and its integration into a real-world business context. Neither do we treat our students' employers with the respect they deserve if they are forced to rely on intuition and final grades because of a lack of "certification" of our graduates.

Information Systems is a difficult profession; gaining a simulator "rating" would help employers choose the most viable candidates and provide students and Universities with a guide to areas of strength and weakness. There are those academics who would throw up their hands in horror at such "trade certification" as part of a University programme, but to do so is to ignore the market demand for such qualifications and the relationship, which Universities must forge with the wider ICT community. Microsoft, Oracle, Borland and so on are currently and increasingly filling this demand, which does not bode well for our Computer Science and Information Systems departments.

This paper is the first step along a significant work in progress trail, but it is worth pursuing. Answer the following questions if doubts remain:

Given the choice of two pilots, one with only theoretical training, the other with theory and a simulator rating, which one would you choose to employ?

Assuming the absence of suicidal tendencies, the answer has to be the latter, so why do we expect ICT employers to, in effect, choose the former?

\section{References}

Baillie, L. (2000). IT employers' skills demands: Do they know what they want? Retrieved from http://www.soi.city.ac.uk/liaison/Conference\%20Papers/HertsPaper.pdf 
Bennett N., Dunne, E., \& Carre, C. (2000). Skills development in higher education and employment. Open University Press

Burd E., Drummond S., (2001) Using peer mentors to aid the project management of group work. University of Durham. Retrieved from http://www.ics.ltsn.ac.uk/pub/groupwork/liz_burd.ppt

Elgood C. (1997). Handbook of management games and simulation. Gower Publishing.

Fakaryildiz, M. (2002). Simulation. Retrieved from http://www.geocities.com/mfakaryilidiz/simulation.html

Fraser-Williams 2000). Retrieved from http://www.buyitnet.org/Case_Studies/Docs/Fraser_Williams.pdf

Garlic, I., \& Jausovec, N. (1999). Multimedia: Differences in processes observed with EEG. Educational Research and Development, 47 (3), 5 -14.

Otago University Assessment Policy. (2003). Retrieved from http://marketing/otago.ac.nz/Marketing/study/assessment_policy.html

Towner N. (2002, November 8). IT Graduates left on the dole. Computerworld

\section{Biography}

Tony Richardson has extensive experience in Information Systems development, ICT recruitment and corporate management. In an ICT career spanning two decades, he has witnessed the shift from mainframes to minis to PC networks and has developed systems for each of these platforms. He has also recruited and managed ICT staff in his role as technical director of a UK software company.

Since his move from the UK to New Zealand in 1986 he has carried out consultancy work for several large New Zealand companies. Since 1995 his main interests have been in ICT education, he is currently head of department at Information Systems, Massey University Albany. 